\title{
Can reanalysis products outperform mesoscale numerical weather prediction models in modeling the wind resource in simple terrain?
}

\author{
Vincent Pronk ${ }^{1}$, Nicola Bodini ${ }^{1}$, Mike Optis ${ }^{1}$, Julie K. Lundquist ${ }^{1,2,3}$, Patrick Moriarty ${ }^{1}$, \\ Caroline Draxl $^{1,3}$, Avi Purkayastha ${ }^{1}$, and Ethan Young ${ }^{1}$ \\ ${ }^{1}$ National Renewable Energy Laboratory, Golden, Colorado USA \\ ${ }^{2}$ Department of Atmospheric and Oceanic Sciences, University of Colorado Boulder, Boulder, Colorado USA \\ ${ }^{3}$ Renewable and Sustainable Energy Institute, Boulder, Colorado USA
}

Correspondence: Nicola Bodini (nicola.bodini@nrel.gov)

\begin{abstract}
Mesoscale numerical weather prediction (NWP) models are generally considered more accurate than reanalysis products in characterizing the wind resource at heights of interest for wind energy, given their finer spatial resolution and more comprehensive physics. However, advancements in the latest ERA-5 reanalysis product motivate an assessment on whether ERA-5 can model wind speeds as well as a state-of-the-art NWP model — the Weather Research and Forecasting (WRF) model. We consider this research question for both simple terrain and offshore applications. Specifically, we compare wind profiles from ERA-5 and the preliminary WRF runs of the Wind Integration National Dataset (WIND) Toolkit Long-term Ensemble Dataset (WTK-LED) to those observed by lidars at site in Oklahoma, United States, and in a U.S. Atlantic offshore wind energy area. We find that ERA-5 shows a significant negative bias $\left(\sim-1 \mathrm{~m} \mathrm{~s}^{-1}\right)$ at both locations, with a larger bias at the land-based site. WTK-LED-predicted wind speed profiles show a slight negative bias $\left(\sim-0.5 \mathrm{~m} \mathrm{~s}^{-1}\right)$ offshore and a slight positive bias $\left(\sim+0.5 \mathrm{~m} \mathrm{~s}^{-1}\right)$ at the land-based site. Surprisingly, we find that ERA-5 outperforms WTK-LED in terms of the centered rootmean-square error (cRMSE) and correlation coefficient, for both the land-based and offshore cases, in all atmospheric stability conditions. We find that WTK-LED's higher cRMSE is caused by its tendency to overpredict the amplitude of the wind speed diurnal cycle both onshore and offshore.
\end{abstract}

Copyright statement. This work was authored in part by the National Renewable Energy Laboratory, operated by Alliance for Sustainable Energy, LLC, for the U.S. Department of Energy (DOE) under Contract No. DE-AC36-08GO28308. Funding provided by the U.S. Department of Energy Office of Energy Efficiency and Renewable Energy Wind Energy Technologies Office and by the National Offshore Wind Research and Development Consortium under Agreement No. CRD-19-16351. The views expressed in the article do not necessarily represent the views of the DOE or the U.S. Government. The U.S. Government retains and the publisher, by accepting the article for publication, acknowledges that the U.S. Government retains a nonexclusive, paid-up, irrevocable, worldwide license to publish or reproduce the published form of this work, or allow others to do so, for U.S. Government purposes. 


\section{Introduction}

Wind energy development requires an accurate characterization of the wind resource at the heights swept out by commercial wind turbine rotor blades (Brower, 2012). Directly measuring the wind speed aloft for the extensive periods of time required for an accurate wind resource assessment can be challenging from both a technical and financial point of view. For land-based sites, there are several major factors that can pose limitations to the installation of tall meteorological towers or remote sensing devices, including complex topography, road access, availability of electrical power, and excessive cost. When considering offshore regions, where an unprecedented growth in installed wind capacity is currently taking place worldwide (Musial et al., 2016; Bureau of Ocean Energy Management, 2018), the challenges connected to having direct observations of hub-height wind speed are even more severe. Floating lidars represent a state-of-the-art source of offshore wind speed observations aloft (Carbon Trust Offshore Wind Accelerator, 2018; OceanTech Services/DNV GL); however, their prohibitive cost still severely limits their availability worldwide. As a result of this constrained scenario, numerical weather prediction (NWP) models at the mesoscale and reanalysis products are frequently used (Draxl et al., 2015; Hahmann et al., 2020; Dörenkämper et al., 2020; Optis et al., 2020b) to characterize the wind resource at the heights of interest for wind energy development, for both land-based and offshore locations.

Reanalysis products are convenient to use given their global coverage and publicly available data. In general, reanalysis products incorporate global measurements of atmospheric variables to produce a 3D-gridded, hindcast, best estimate of the state of the atmosphere. Reanalysis products typically provide multiple decades of data and are regularly updated (Schwartz et al., 1999; Compo et al., 2011; Gelaro et al., 2017; Bloomfield et al., 2018). While very convenient for wind resource studies, the coarse spatial ( $\sim 1$ degree) and temporal resolution (usually 6 hours) can produce inaccurate estimates of the wind resource. Specifically, previous validation studies at land-based sites have led to a wide variety of uncertainties associated with the product used, the location, the vertical level, and the vertical and horizontal spatial approximation technique used (Kubik et al., 2013; Rose and Apt, 2015; Ramon et al., 2019; Molina et al.). Offshore, reanalysis products generally have better skills, and they have been used to create atlases of either wind resource or wind energy potential. Zheng et al. (2018) quantified the global offshore wind resource using the ERA-interim reanalysis product (Dee et al., 2011), while Soares et al. (2020) recently evaluated the global offshore wind energy potential using the more recent ERA-5 product (Hersbach et al., 2020). However, validating such reanalysis predictions against hub-height observations has rarely been done because of the scarcity of offshore wind speed observations at the heights of interest for commercial wind development. Sheridan et al. (2020) recently validated three reanalysis products using data at one single height from a floating lidar in the U.S. Eastern Seaboard.

By comparison, NWP models generally provide more accurate estimates of the wind resource but are much more expensive to run. NWP models use a large-scale atmospheric product, such as a reanalysis product, as external forcing, while using higher spatial and temporal resolution to simulate more comprehensive physics. Several studies have applied NWP models to wind resource assessment (an extensive review can be found in Al-Yahyai et al. (2010)), at a variety of temporal and spatial scales. Draxl et al. (2015) developed an NWP model-based wind speed atlas for the continental United States, and similar efforts have been completed for the European continent (Hahmann et al., 2020; Dörenkämper et al., 2020). Recently, NWP models have 
also been used to create offshore wind resource assessment data sets (Rybchuk et al., 2021). By providing high-resolution wind speed data, NWP models are beneficial for assessing the wind resource at specific sites of interest for wind energy development. However, the development of NWP-based wind resource data sets is computationally expensive, especially when considering the fine horizontal, vertical, and temporal resolutions, as well as long-term periods of record.

Within this context, the latest reanalysis product, ERA-5 (Hersbach et al., 2020), comes with significant advancements compared to previous products, in terms of both spatial ( $\sim 32-\mathrm{km}$ horizontally) and temporal (1 hour) resolutions. These improvements motivate an analysis on whether ERA-5 is capable of modeling wind speeds with an accuracy comparable if not superior to the state-of-the-art mesoscale NWP model - the Weather Research and Forecasting (WRF) model (Skamarock et al., 2019), as part of the initial runs for the WIND Toolkit Long-term Ensemble Dataset (WTK-LED). For this evaluation, we consider vertical profiles of wind speed up to $200 \mathrm{~m}$ and focus on two sites that represent typical conditions for present and future wind energy development in the United States. As an example of land-based site, we consider the U.S. Department of Energy's Atmospheric Radiation Measurement (ARM) Southern Great Plains (SGP) measurement site near Lamont, Oklahoma. Offshore, we focus on two floating lidars recently developed by the New York State Energy Research and Development Authority (NYSERDA) along the U.S. Eastern Seaboard. We describe the data sets in Section 2, where we also introduce the performance metrics we adopt in the analysis. The results of the evaluation of both WTK-LED and ERA-5 are presented in Section 3, where we also focus on the variability of the assessed performance with height and atmospheric stability. Finally, we conclude our analysis and suggest future work in Section 4.

\section{Data and Methods}

While complex terrain likely remains too challenging for an accurate wind speed representation by ERA-5 and will be the subject of future work, here we focus our analysis on simple terrain. More in detail, we perform a reanalysis and mesoscale model validation at two locations-one on land and one offshore. At both sites, publicly available hub-height wind speed observations are used.

For our land-based test case, we focus on the ARM SGP Central Facility (C1) site near Lamont, Oklahoma (Figure 1). The SGP Central Facility site is located in a fairly flat area with an elevation ranging from just $\sim 270$ meters (m)-390-m above sea level in the area surrounding the site. As a result, the land is used primarily for agricultural purposes. Several wind power plants were built in the area in the last decade, as shown in the map in Figure 1. For our analysis, we consider data from January 01, 2018 to December 31, 2018. While both ERA-5 and lidar observations at the site cover a much longer time period, preliminary WTK-LED data for the region are available only for this one-year period.

Offshore, we use wind speed observations from two floating lidars along the U.S. Eastern Seaboard, where several wind energy lease areas have been planned (of Ocean Energy Management, 2021) for future offshore wind energy development (Figure 1). We consider data from September 01, 2019, to August 31, 2020 (lidar data are not available before this period and WTK-LED was not run after it). 


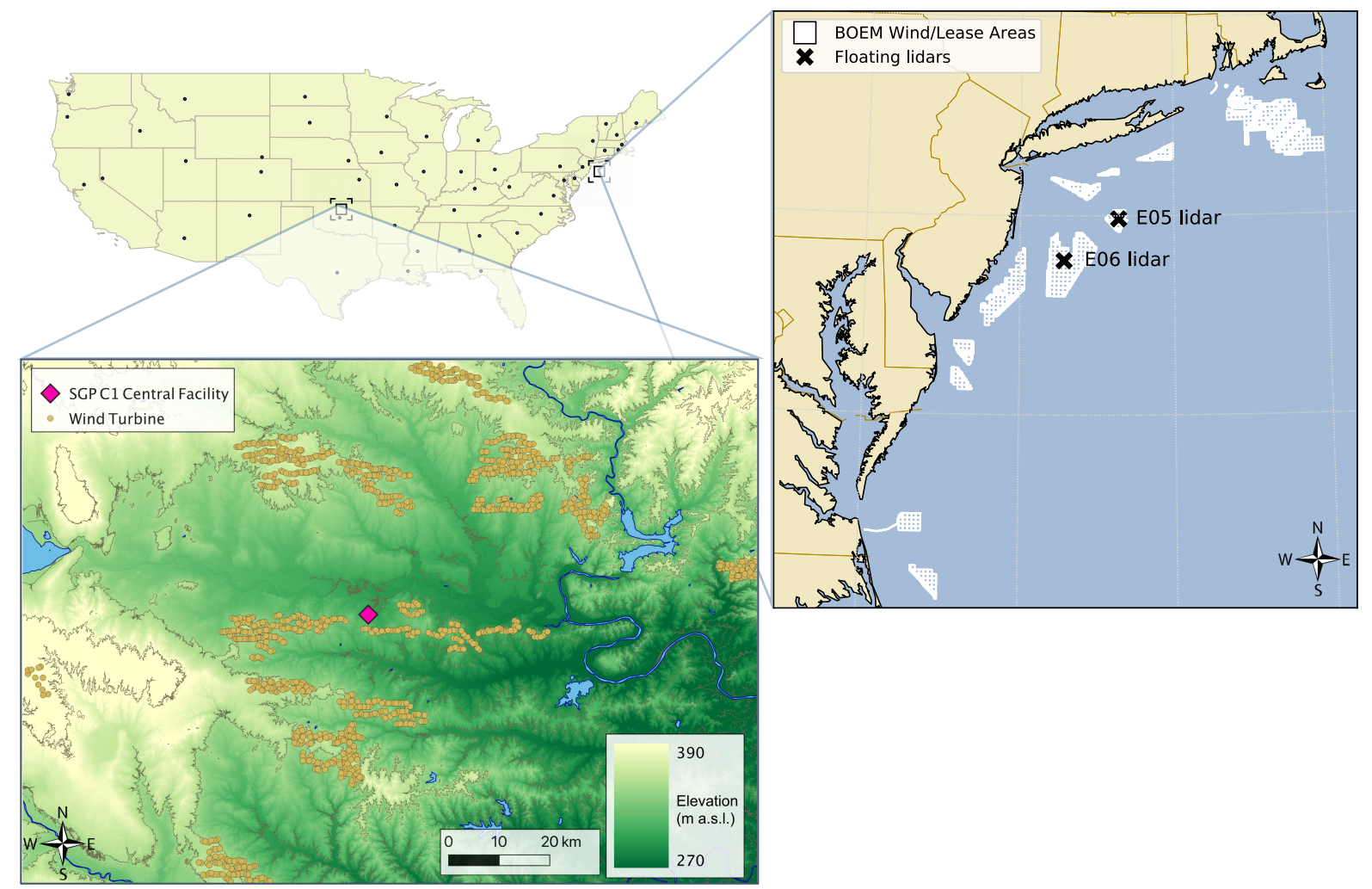

Figure 1. Map of the two sites considered in our validation analysis. Digital Elevation Model data courtesy of the U.S. Geological Survey.

\subsection{Observations}

At the SGP Central Facility site, we consider observations from a Halo Streamline lidar (Newsom, 2012). We obtained horizontal wind speed data from full $360^{\circ}$ conical scans by the lidar, which were performed approximately every 15 minutes, with 1 minute needed to complete each scan. To obtain the horizontal wind speed from the line-of-sight velocity from these scans, we used the velocity-azimuth-display approach from Frehlich et al. (2006). In doing this, the horizontal wind field is assumed to be homogeneous over the scan volume, and the average vertical velocity is assumed to be zero (Browning and Wexler, 1968). As in Bodini and Optis (2020), we discard any measurements that have a signal-to-noise ratio lower than $-21 \mathrm{~dB}$ or higher than $+5 \mathrm{~dB}$, and any measurements from time periods with precipitation that may significantly lower the accuracy of the measurements. The wind speed data are then averaged to obtain hourly average data. For our study, we consider data from 6 range gates, which correspond to heights of 65-, 91-, 117-, 143-, 169-, and 195-m above sea level. Data at lower heights were not used because of poor data quality. The analysis of the lidar data reveals how the site experiences winds mainly from the south (see 91-m wind rose in Figure 2a), with more variability observed in winter months. Many wind plants were built around the SGP site in the last decade. At the Central Facility site, the closest wind turbines are about $3.5 \mathrm{~km}$ away, and Bodini et al. 
(a)

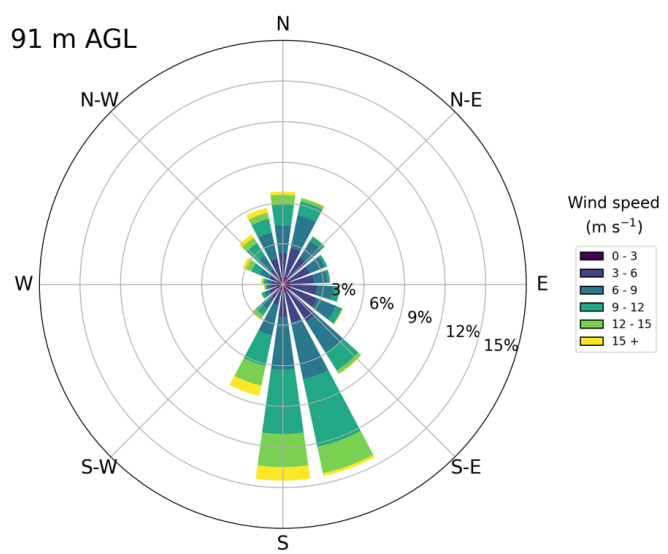

(c)

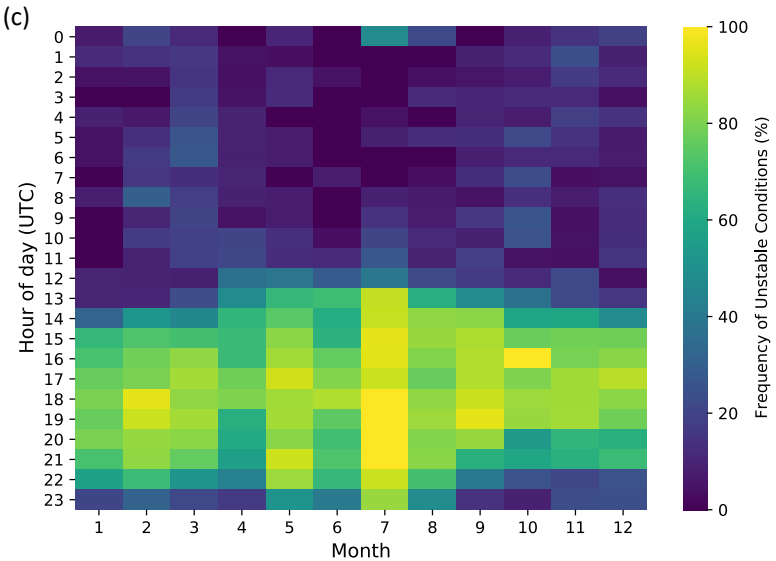

(b)

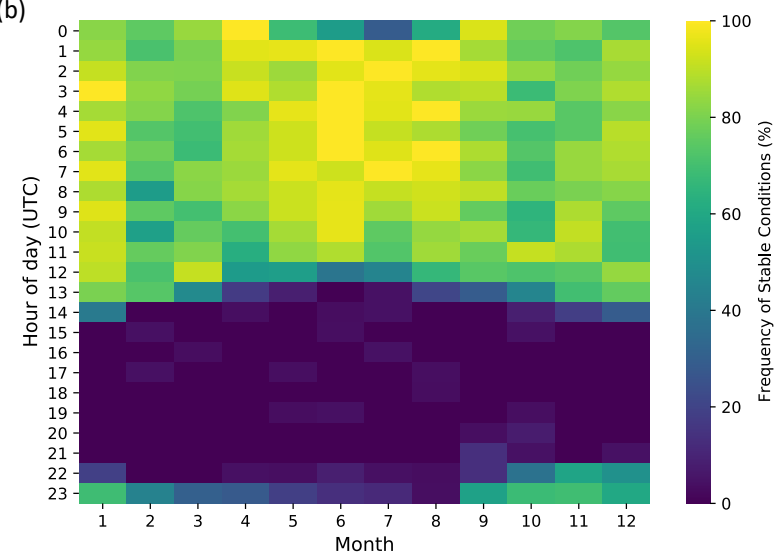

(d)

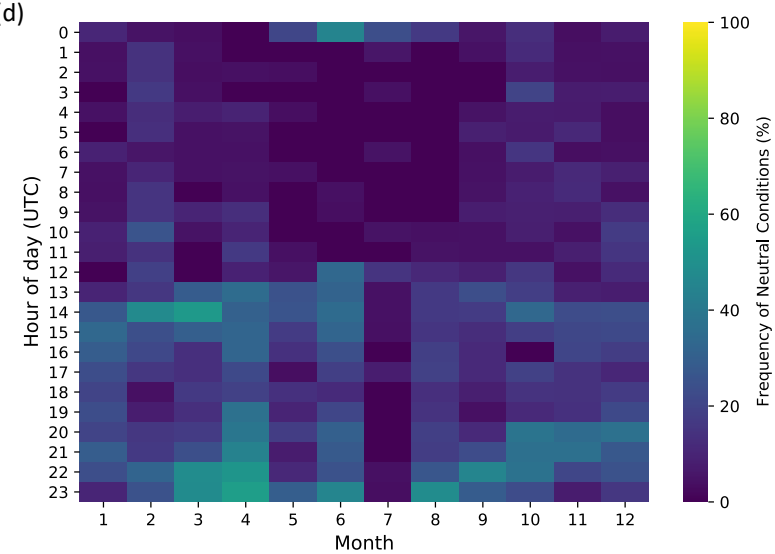

Figure 2. (a) Wind rose showing the distribution of wind speeds at 91-m AGL for 2018, using lidar observations at the SGP Central Facility site. (b) 24-x-12 heat map of the frequency of stable conditions at the site, classified in terms of the surface Obukhov length. (c) Same, but for unstable and (d) neutral conditions.

(in review) showed how the site is impacted by wind plant wakes for southerly flow, especially in nighttime stable conditions. We classify atmospheric stability using near-surface (4-m above ground level (AGL)) observations from a sonic anemometer at the $\mathrm{C} 1$ site. We calculate the Obukhov length as:

$\mathrm{L}=-\frac{\overline{T_{v}} \cdot u_{*}^{3}}{k \cdot g \cdot \overline{w^{\prime} T_{v}^{\prime}}}$

where $k=0.4$ is the von Kármán constant; $g=9.81 \mathrm{~m} \mathrm{~s}^{-2}$ is the acceleration due to gravity; $T_{v}$ is the virtual temperature $(\mathrm{K}) ; u_{*}=\left({\overline{u^{\prime} w^{\prime}}}^{2}+{\overline{v^{\prime} w^{\prime}}}^{2}\right)^{1 / 4}$ is the friction velocity (m s s ); and $\overline{w^{\prime} T_{v}^{\prime}}$ is the kinematic virtual temperature flux $\left(\mathrm{K} \mathrm{m} \mathrm{s} \mathrm{s}^{-1}\right)$. All Reynolds decompositions are calculated with a 30-minute averaging period (De Franceschi and Zardi, 2003; Babić et al., 2012). We consider stable conditions for $0 \mathrm{~m}<L \leq 200 \mathrm{~m}$, unstable conditions for $-200 \mathrm{~m} \leq L<0 \mathrm{~m}$, near-neutral otherwise. Figures $2 \mathrm{~b}, \mathrm{c}$, and d show $24-\mathrm{x}-12$ heat maps of the frequency of stable, unstable, and neutral conditions, respectively. A clear 
diurnal pattern emerges, with stable conditions being typical of the nighttime hours, and unstable conditions occurring in daytime convective periods. Also, summer shows more extended unstable cases compared to winter months. On the other hand, near-neutral conditions are relatively rare at the site, occurring most often during morning and evening transitions.

Offshore, we consider observations of wind speed from two floating lidars off the coast of New Jersey. The New York State Energy Research and Development Authority (NYSERDA) recently deployed these lidars and made their data publicly available (OceanTech Services/DNV GL). The lidar on buoy E05 is located at $39.97^{\circ} \mathrm{N}, 72.72^{\circ} \mathrm{W}$; the buoy E06 lidar is located at $39.55^{\circ} \mathrm{N}, 73.43^{\circ} \mathrm{W}$. Wind speed and wind direction data for both lidars are available every $20 \mathrm{~m}$ from $58-\mathrm{m}$ to $198-\mathrm{m}$ above sea level. At these sites, wind mainly flows from the southwest and northwest, as is the case further east in this region (Bodini et al., 2019, 2020) and it is generally stronger than what was observed at SGP, as shown in the wind rose at 98-m above sea level from lidar E05 in Figure 3a. Due to the lack of observations from which atmospheric stability metrics can be calculated, we use WTK-LED data to classify atmospheric stability as a function of the bulk Richardson number from $0 \mathrm{~m}-200 \mathrm{~m}$ above the surface. The bulk Richardson number is calculated as:

$R i_{b}=\frac{g}{\overline{\theta_{v}}} \frac{\Delta z \Delta \theta_{v}}{(\Delta U)^{2}+(\Delta V)^{2}}$

where $g$ is the gravitational acceleration, $\overline{\theta_{v}}$ is the average absolute virtual potential temperature across the considered layer of thickness $\Delta z, \Delta \theta_{v}$ is the virtual potential temperature difference across the layer, and $\Delta U$ and $\Delta V$ are the changes in the horizontal wind components across that same layer. We use values of $R i_{b}>0.025$ to classify stable conditions, $R i_{b}<-0.025$ for unstable conditions, and all other values as near-neutral conditions. Figures $3 \mathrm{~b}$ and c show the 24-x-12 heat maps of the frequency of stable and unstable conditions, respectively. While a clear diurnal pattern emerged when looking at similar plots at SGP, here we find little diurnal variability, but a strong seasonal cycle. Summer months show the most instances of stable conditions, while winter months show primarily unstable conditions. Finally, near-neutral conditions account for up to half of the cases in certain times and show little variability across both the diurnal and annual scales.

\subsection{NWP model setup}

At SGP, we use WRF model data for 2018 from the preliminary National Renewable Energy Laboratory's (NREL's) Wind Integration National Dataset (WIND) Toolkit Long-term Ensemble Dataset (WTK-LED), which will update the original WIND Toolkit (WTK) [Lieberman-Cribbin et al. (2014); King et al. (2014); Draxl et al. (2015)]. The main WRF attributes in the WTKLED setup are summarized in Table 1. The simulations were initialized every month, and each simulation was initialized 2 days prior to and run up to 1 day after the end of each month. The first day of each monthly run is used as spin-up time for the model, while the second and last days are used to combine monthly runs. Model output is available at 5-minute resolution, and we average the data at hourly resolution to perform the validation analysis. We consider data from the closest 2-km grid cell to the location of the lidar (the difference in terrain height between this WRF grid cell and the actual lidar location is $<3$ $\mathrm{m})$. To match the heights at which lidar observations are available, we linearly interpolate the WRF data from the two closest levels. Given the high near-surface resolution used (see Table 1), we expect this linear interpolation to introduce only a small additional error to the analysis. 
(a)

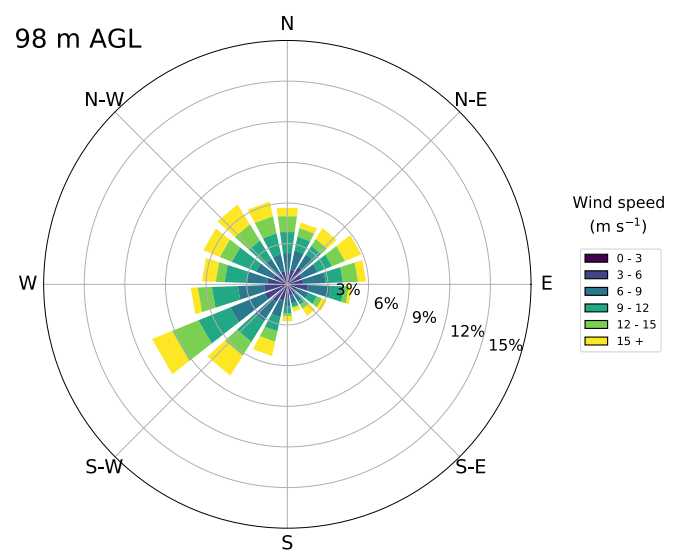

(c)

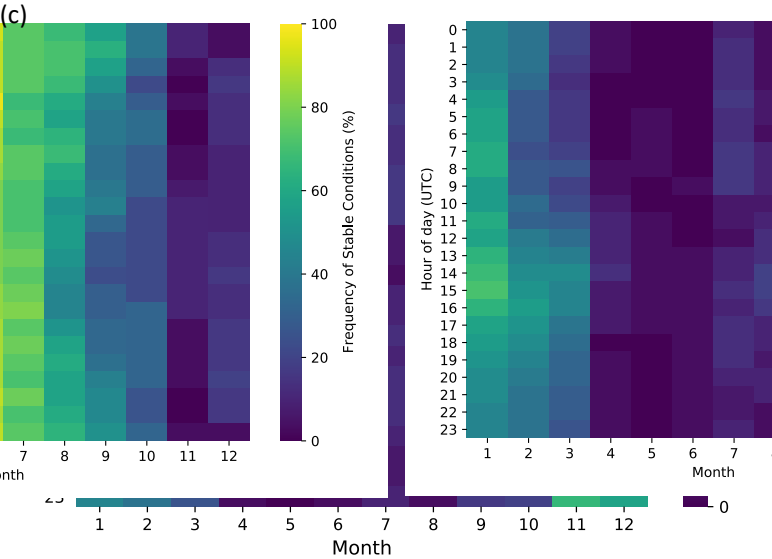

(b)

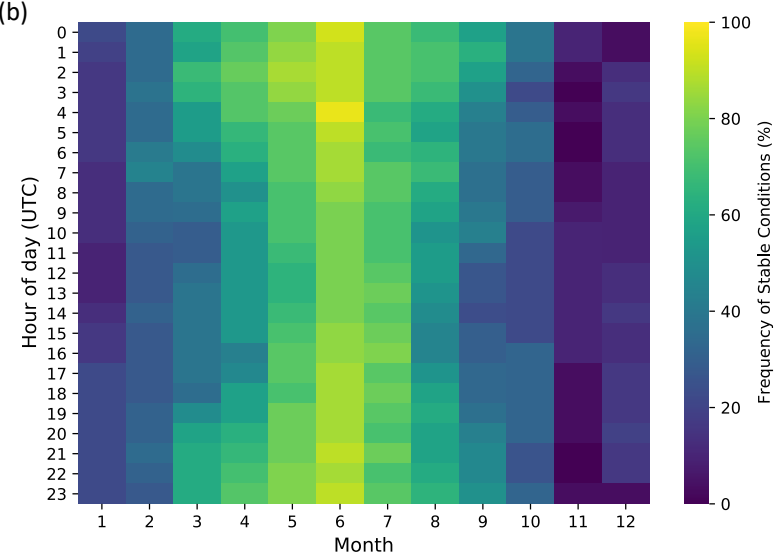

(d)

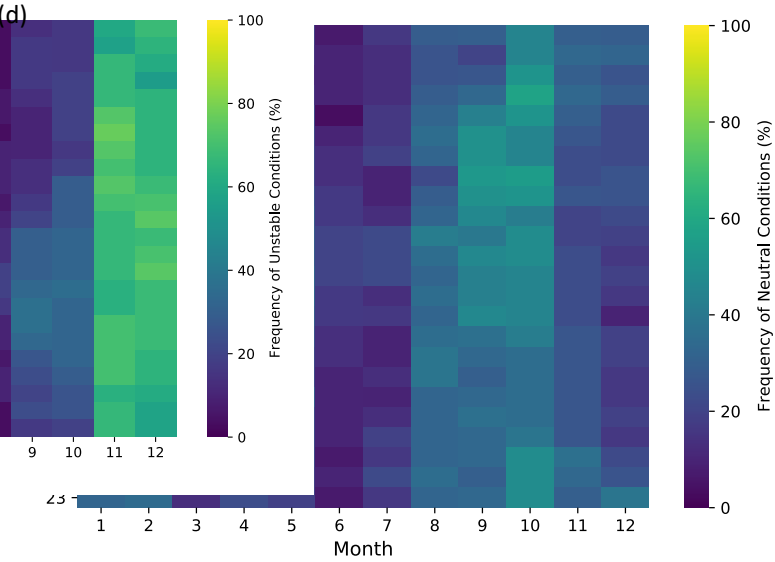

Figure 3. (a) Wind rose showing the distribution of wind speeds at 98-m AGL for September 2019 to August 2020, using observations from the E05 floating lidar. (b) 24-x-12 heat map of the frequency of stable conditions at the E05 lidar location, classified in terms of the WTK-LED-based bulk Richardson number calculated between $0 \mathrm{~m}$ and $200 \mathrm{~m}$ ASL. (c) Same, but for unstable and (d) neutral conditions. Results from the E06 lidar are included in the Supplementary Materials.

Offshore, we use WRF data from the offshore version of NREL's WTK-LED. A summary of the model setup is provided in Table 1. Similar to the land-based case, we select WTK-LED data from the closest grid cell to the location of each of the two floating lidars and linearly interpolate the WRF vertical levels to match the heights of the lidar data.

\subsection{ERA-5 reanalysis}

We use the state-of-the-art ERA-5 reanalysis product (Hersbach et al., 2020), to compare its skill in assessing wind resource with that of the WTK-LED product. ERA-5 provides hourly average data at 137 vertical levels and an $\sim 31$-km horizontal resolution. In our analysis, we considered vertical levels corresponding to heights of 54-, 79-, 106-, 137-, 170-, and 205-m above sea level. As done for WTK-LED, these heights are then linearly interpolated to match those of the lidar observations. We use 
Table 1. Key attributes of the WRF simulations in WTK-LED setup used in this study.

\begin{tabular}{|c|c|c|}
\hline \multirow{2}{*}{ Feature } & \multicolumn{2}{|c|}{ Specification } \\
\hline & Offshore & Land-based \\
\hline WRF version & \multicolumn{2}{|l|}{4.2 .1} \\
\hline Grid spacing & $6 \mathrm{~km}, 2 \mathrm{~km}$ (nested) & $2 \mathrm{~km}$ \\
\hline Output time resolution & \multicolumn{2}{|c|}{5 minutes } \\
\hline Vertical levels & \multicolumn{2}{|l|}{61} \\
\hline Near-surface-level heights (m) & \multicolumn{2}{|c|}{$12,34,52,69,86,107,134,165,200$} \\
\hline Atmospheric forcing & \multicolumn{2}{|c|}{ ERA-5 reanalysis } \\
\hline \multirow[t]{2}{*}{ Atmospheric nudging } & Spectral nudging (6-km domain) & Spectral nudging \\
\hline & applied every 6 hours & applied every 3 hours \\
\hline Planetary boundary layer scheme & \multicolumn{2}{|c|}{ Mellor-Yamada-Nakanishi-Niino Level 2.5} \\
\hline Microphysics & Ferrier & Morrison double-moment \\
\hline Longwave radiation & \multicolumn{2}{|c|}{ Rapid radiative transfer model } \\
\hline Shortwave radiation & \multicolumn{2}{|c|}{ Rapid radiative transfer model } \\
\hline \multirow[t]{2}{*}{ Topographic database } & Global multiresolution terrain & vation data from the \\
\hline & \multirow{2}{*}{\multicolumn{2}{|c|}{$\begin{array}{c}\text { U.S. Geological Survey and National Geospatial-Intelligence Agency } \\
\text { Moderate Resolution Imaging Spectroradiometer } 30 \mathrm{~s}\end{array}$}} \\
\hline Land-use data & & \\
\hline Cumulus parameterization & Kain-Fritsch (6-km domain) & None \\
\hline Sea surface temperature product & Operational Sea Surface Temperature & None \\
\hline & and Sea Ice Analysis (OSTIA) & \\
\hline
\end{tabular}

data from the ERA-5 grid point which is closest in space to the considered lidars. Sheridan et al. (2020) recently confirmed that selecting the closest grid point generally leads to better reanalysis performance compared to a linear interpolation of the four surrounding grid points, while Livingston and Lundquist (2020) used a bilinear interpolation. The coordinates of the selected ERA-5 grid point at SGP are $36.5^{\circ} \mathrm{N}$ and $97.5^{\circ} \mathrm{W}$; offshore, we use data from the $40^{\circ} \mathrm{N}, 72.75^{\circ} \mathrm{W}$ grid point to compare with the E05 lidar data, and at $39.5^{\circ} \mathrm{N}, 73.5^{\circ} \mathrm{W}$ to compare with the E06 lidar data.

\subsection{Performance metrics}

To quantify the skills of WTK-LED and ERA-5 in predicting the observed wind resource, we calculate, at all of the considered heights, four performance metrics, as recommended in Optis et al. (2020a).

In general, it is important to decompose a model error into bias, which quantifies the difference between modeled and observed data; and random error, which quantifies the variability of the modeled data around the mean. We decompose the rootmean-square error (RMSE) into a bias component and an "unbiased" or "centered" component of RMSE (cRMSE), following 
the approach in Taylor (2001). We calculate bias as:

$\operatorname{Bias}=\bar{p}-\bar{o}$

where $\bar{p}$ is the mean of the modeled (by either WTK-LED or ERA-5) estimates and $\bar{o}$ is the mean of the lidar observations. A perfect prediction would have a bias of 0 . Next, we calculate the cRMSE as:

$\operatorname{cRMSE}=\left[\frac{1}{N} \sum_{n=1}^{N}\left[\left(p_{n}-\bar{p}\right)-\left(o_{n}-\bar{o}\right)\right]^{2}\right]^{1 / 2}$

where $N$ is the number of data points in the considered time series, and $p_{n}$ and $o_{n}$ indicate the time series values of modeled and observed wind speed, respectively. A perfect prediction would have a cRMSE of 0 .

As a third performance metric, we calculate the square of the Pearson's correlation coefficient between observed and modeled wind. The correlation coefficient $r$ measures how strong the correspondence between two variables is, and it is calculated as:

$r=\frac{\frac{1}{N} \sum_{n=1}^{N}\left(p_{n}-\bar{p}\right)-\left(o_{n}-\bar{o}\right)}{\sigma_{p} \sigma_{o}}$

where $\sigma_{p}$ and $\sigma_{o}$ are the standard deviations of the modeled and observed data, respectively. A perfect prediction would have a correlation coefficient of 1 .

Last, we use the Earth-mover's distance (EMD), also known as the Wasserstein distance (?Hahmann et al., 2020), which measures the difference between two distributions. EMD is calculated as the area between two cumulative distribution functions (here, modeled and observed wind speed). This metric is an improvement on the bias metric and will catch cases where bias may be zero, despite having different modeled and observed wind speed distributions. The distribution of a perfect prediction would have an EMD of 0.

\section{Results}

\subsection{Mean performance}

In Figure 4, we compare the mean wind profiles from all three data sources at SGP and the NYSERDA E05 lidar. (Results from the E06 lidar are included in the Supplementary Materials because no major differences between the results from the two lidars were found.) In each panel, the solid lines indicate the mean wind profile and the shaded bands around them represent \pm the standard deviation of the data. On average, the wind resource is stronger offshore. At both sites, the ERA-5 mean wind profile underestimates the observed wind resource. Conversely, WTK-LED shows a slight overestimation of the mean wind profile at the land-based site and a slight underestimation offshore. However, in all cases, a large variability emerges so that a more detailed investigation, beyond an annual average, is required.

We then consider the four mean performance metrics introduced in Section 2.4 for both WTK-LED and ERA-5 calculated at the two sites (Figure 5). The WTK-LED-predicted wind speed profiles show a slight positive bias $\left(\sim+0.5 \mathrm{~m} \mathrm{~s}^{-1}\right)$ at the land-based location and a slight negative bias $\left(\sim-0.5 \mathrm{~m} \mathrm{~s}^{-1}\right)$ offshore. However, ERA-5 shows a significant negative bias at 
(a)

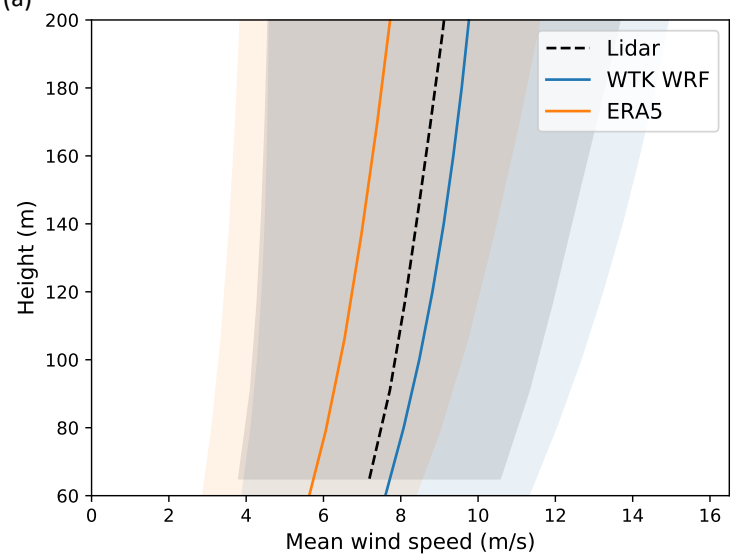

(b)

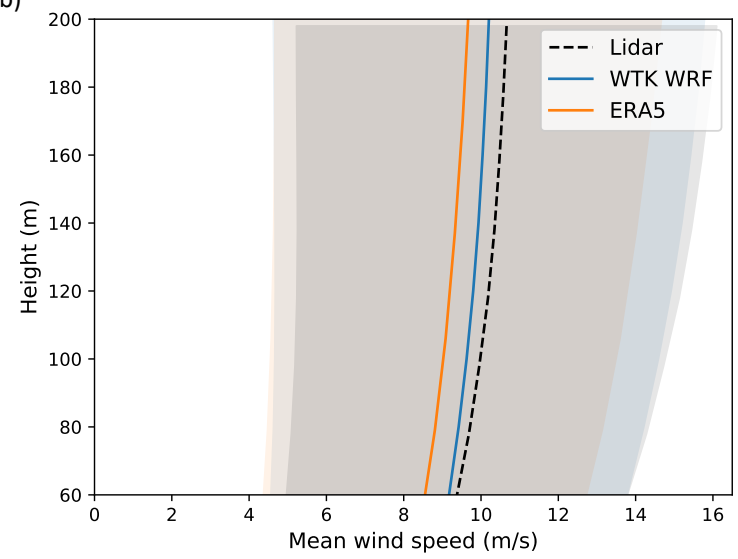

Figure 4. Mean vertical wind speed profiles for all three data sources at (a) the land-based SGP site and (b) the offshore E05 floating lidar. The shaded bands represent \pm the standard deviation of the data.

both locations, especially at SGP, where the bias is $\sim-1.5 \mathrm{~m} \mathrm{~s}^{-1}$. In general, we find little variability with height, with just a slight degradation of the bias with height for both WTK-LED and ERA-5. When considering the cRMSE, however, we find an opposite situation, with ERA-5 outperforming WTK-LED at both locations at all heights. We find satisfactory correlation at both sites, once again with ERA-5 providing slightly better values. The offshore location shows larger values $\left(r^{2}>0.85\right.$ for both ERA-5 and WTK-LED at all heights), likely because of the positive effects of the simpler topography on the skills of both data sources. Interestingly, we find a slight increase in $r^{2}$ with height, especially at SGP. Finally, when looking at the EMD, WTK-LED significantly outperforms ERA-5 at both sites, once again with the offshore site showing better results for both data sources compared to the land-based location. Given the difference in relative performance between WTK-LED and ERA-5 when considering different metrics, we will investigate the impact of atmospheric stability, diurnal, and seasonal cycles in the next sections to investigate the potential reasons for such variability.

\subsection{Impact of atmospheric stability}

To assess whether the relative performance between ERA-5 and WTK-LED holds in all atmospheric stability conditions, we segregate the data at both sites. As detailed in Sections 2.1.1 and 2.2.1, we classify atmospheric stability at SGP based on the near-surface observed Obukhov length, while offshore we base our classification on the WTK-LED-modeled bulk Richardson number, in absence of direct observations from which atmospheric stability parameters can be derived. We then calculate the vertical profiles of the four performance metrics for each stability class at the two sites (Figure 6). The relative performance between ERA-5 and WTK-LED observed from the mean profiles with no data segregation still holds in all stability conditions: WTK-LED outperforms ERA-5 for bias and EMD, while ERA-5 shows a better performance when considering cRMSE and $r^{2}$. When analyzing how the performance of each data source varies with atmospheric stability, interesting considerations emerge. 

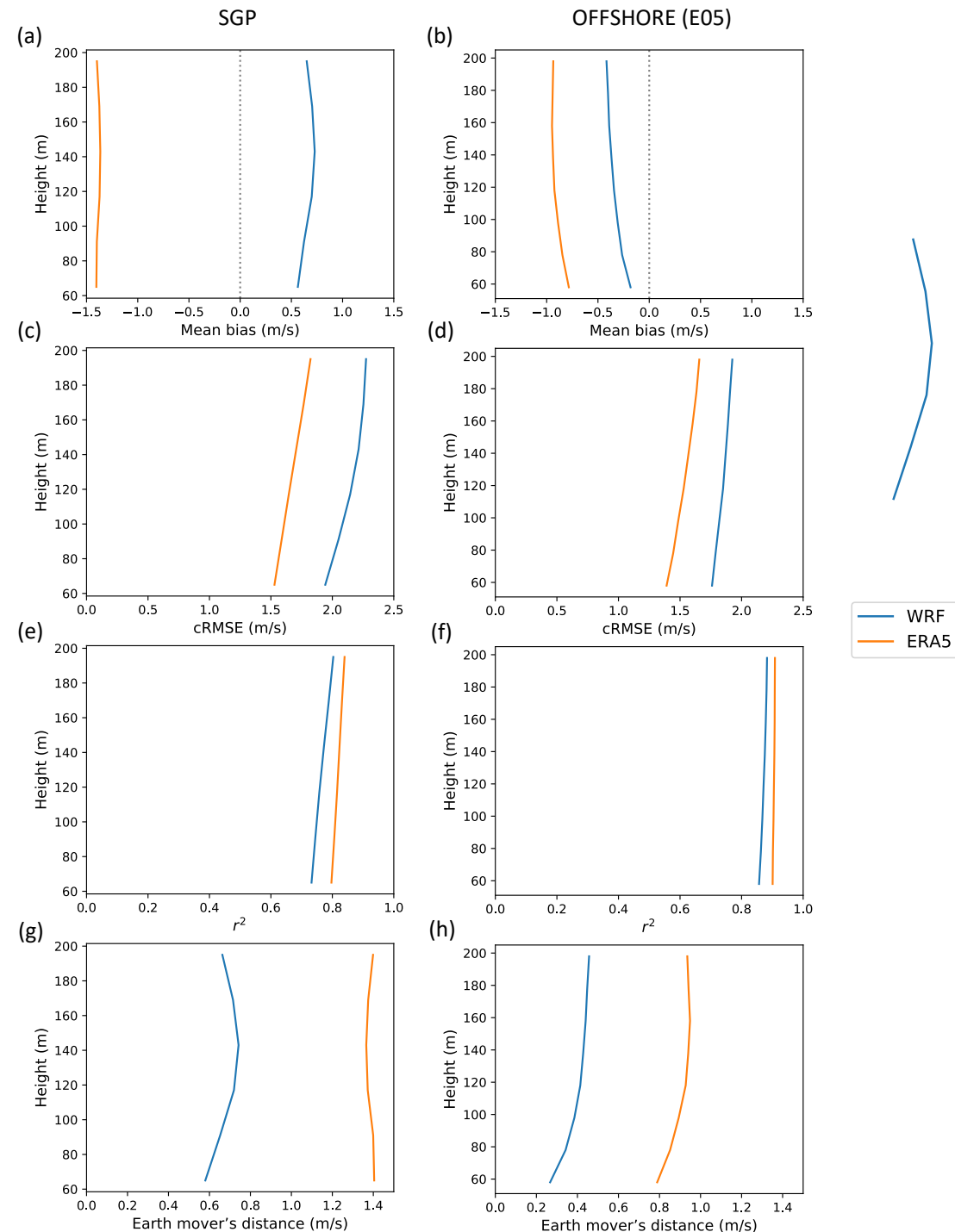

Figure 5. Vertical profiles of mean bias, cRMSE, $r^{2}$, and EMD at the SGP C1 site (left) and the E05 lidar (right). Results from the E06 lidar are included in the Supplementary Materials.

At SGP, WTK-LED shows the best agreement with observations in unstable conditions, with a near-zero bias and EMD at all considered heights, and its lowest values of cRMSE. However, stable cases seem the most challenging to model for WTK-LED, as also noticed by Smith et al. $(2018,2019)$ with respect to the challenges for WRF to accurately model the frequent nocturnal low-level jets in the region. ERA-5 also performs well in unstable conditions, but ERA's stable cases outperform neutral conditions, which show worse performance in terms of bias, cRMSE, and EMD. Little variability with stability emerges when considering the $r^{2}$ metric. 

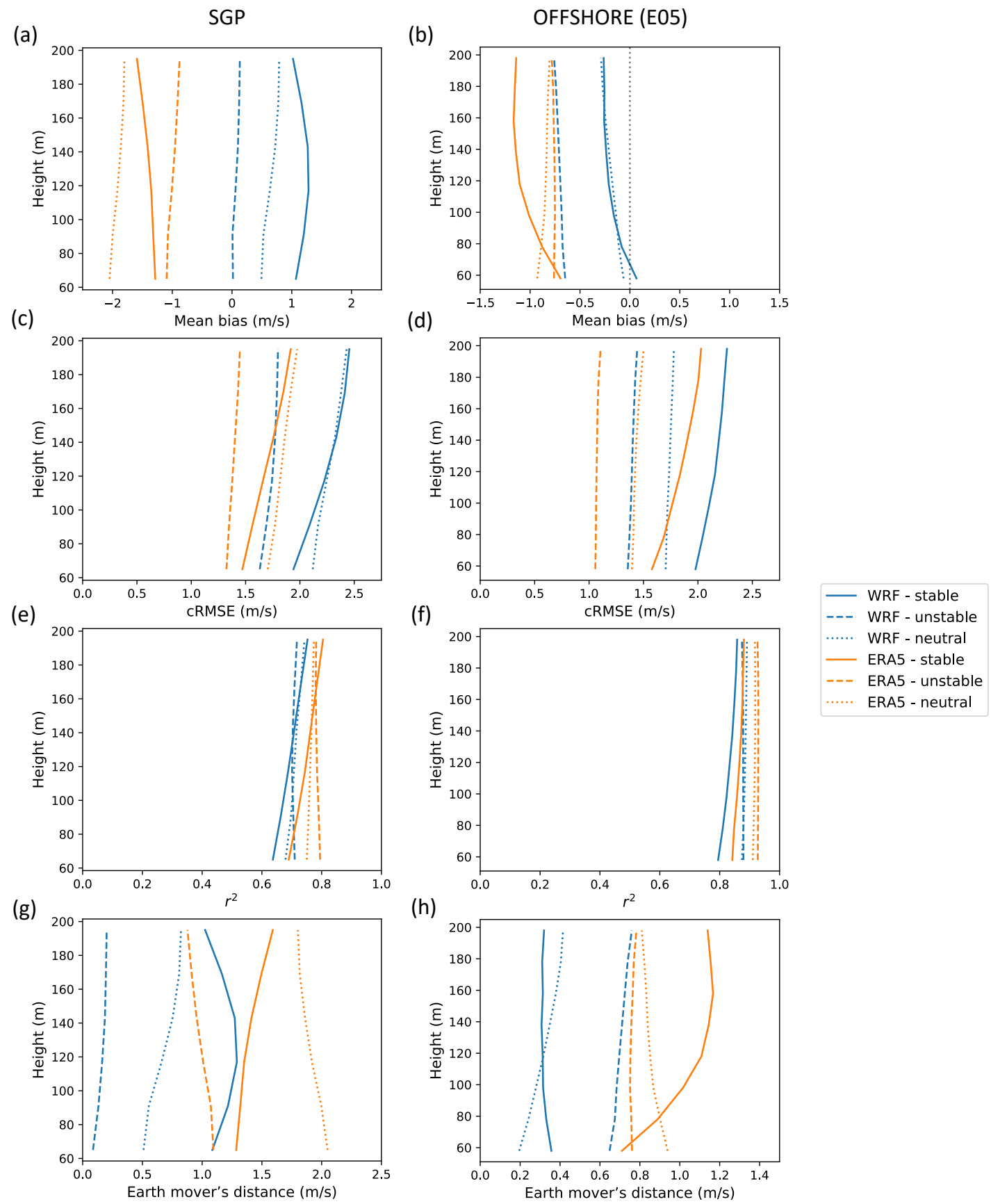

Figure 6. Vertical profiles of performance metrics segregated by atmospheric stability at the SGP C1 site (left) and at the location of the E05 lidar (right). Results from the E06 lidar are included in the Supplementary Materials. 

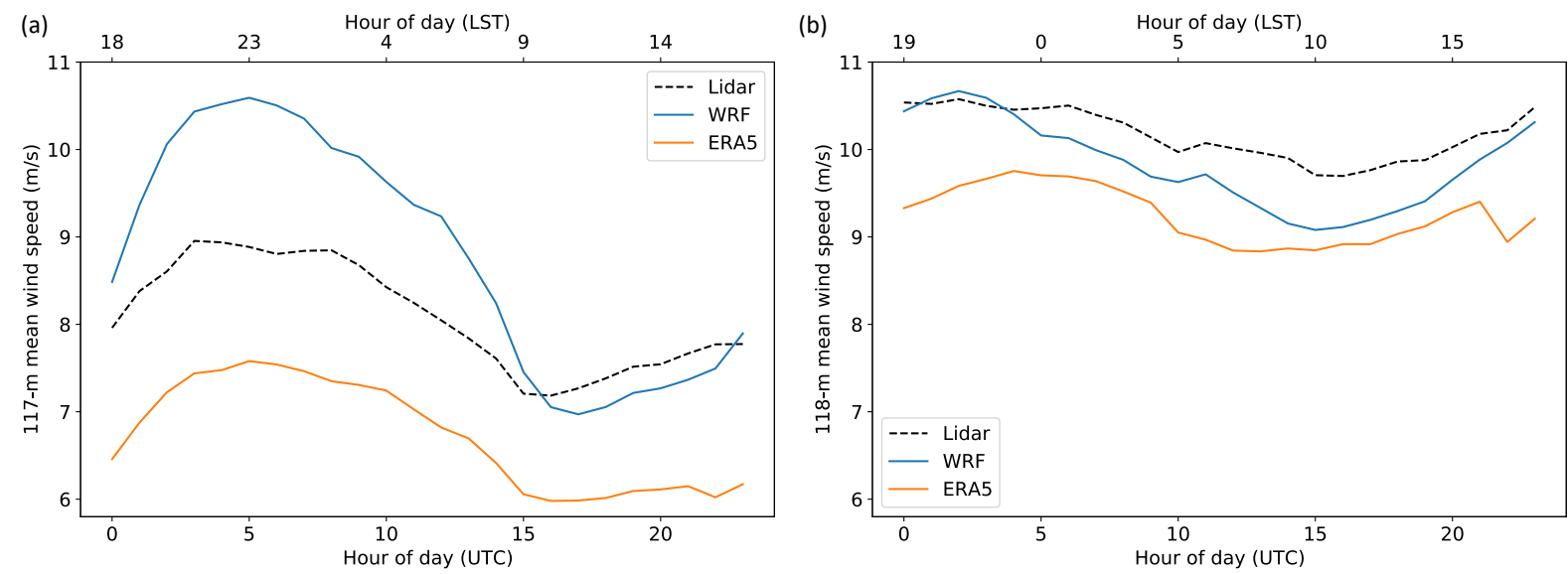

Figure 7. Average diurnal cycle of the $\sim 120$-m wind speed from lidar, WRF, and ERA-5 at (a) the SGP C1 site and (b) the location of the E05 lidar. Results from the E06 lidar are included in the Supplementary Materials.

At the offshore site, slightly different considerations apply. While unstable conditions still show the best performance in terms of cRMSE, stable and neutral cases outperform unstable conditions when considering bias and EMD, with again little variability in terms of correlation. For ERA-5, unstable cases show the best performance across all the considered metrics, followed by neutral conditions and, last, stable periods.

\subsection{Impact of diurnal and seasonal variability}

To further investigate the reasons for WTK-LED displaying a worse performance in its cRMSE and $r^{2}$ compared to ERA-5, we analyze the average diurnal cycle at both locations (Figure 7). A clear diurnal variability emerges at both locations, with higher wind speeds occurring at night (SGP) or evening (offshore). At SGP, this variability is consistent with the frequent nocturnal low-level jets that have been observed at the site (Song et al., 2005; Greene et al., 2009). We find that ERA-5 well captures the amplitude of the observed diurnal cycle with a negative bias that remains nearly constant throughout the average day. By contrast, WTK-LED overestimates the amplitude of the average diurnal cycle, especially at the land-based location. At SGP, we find that WTK-LED significantly overestimates the nocturnal high wind speeds, whereas it well captures the daytime wind regime. Offshore, a nearly opposite situation occurs as WTK-LED exhibits skill in predicting the strong nocturnal winds, but slightly underestimates the weaker daytime winds. This exaggeration of the diurnal cycle by WTK-LED leads to its worst performance, compared to ERA-5, when considering the cRMSE and correlation coefficient at both locations.

To further break down the temporal variability of the relative performance of WTK-LED and ERA-5, we look at the diurnal and seasonal variability of the four performance metrics at both test sites. To do so, we build $24-\mathrm{x}-12$ heat maps of the four metrics by partitioning data by both hour of day and month. We show results for the land-based test case in Figure 8; the offshore test case is shown in Figure 9. We show results at 91-m AGL at SGP, at 98-m offshore, considered as a proxy for wind turbine hub-height, and we note that no significant variability of the metrics with height was found. At SGP, the 


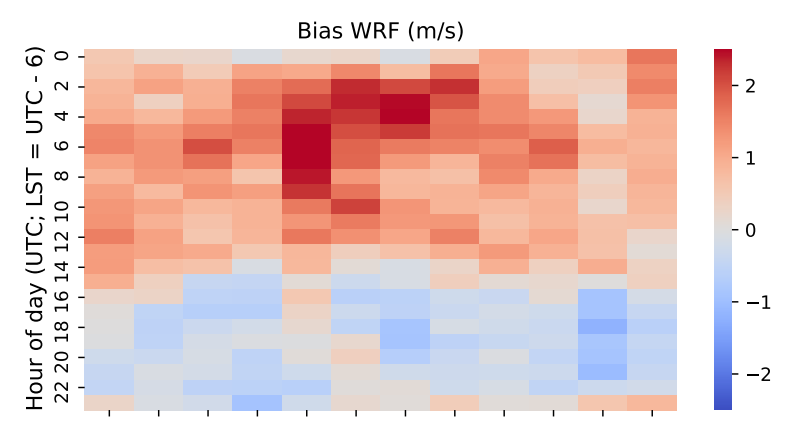

CRMSE WRF - CRMSE ERA5 (m/s)
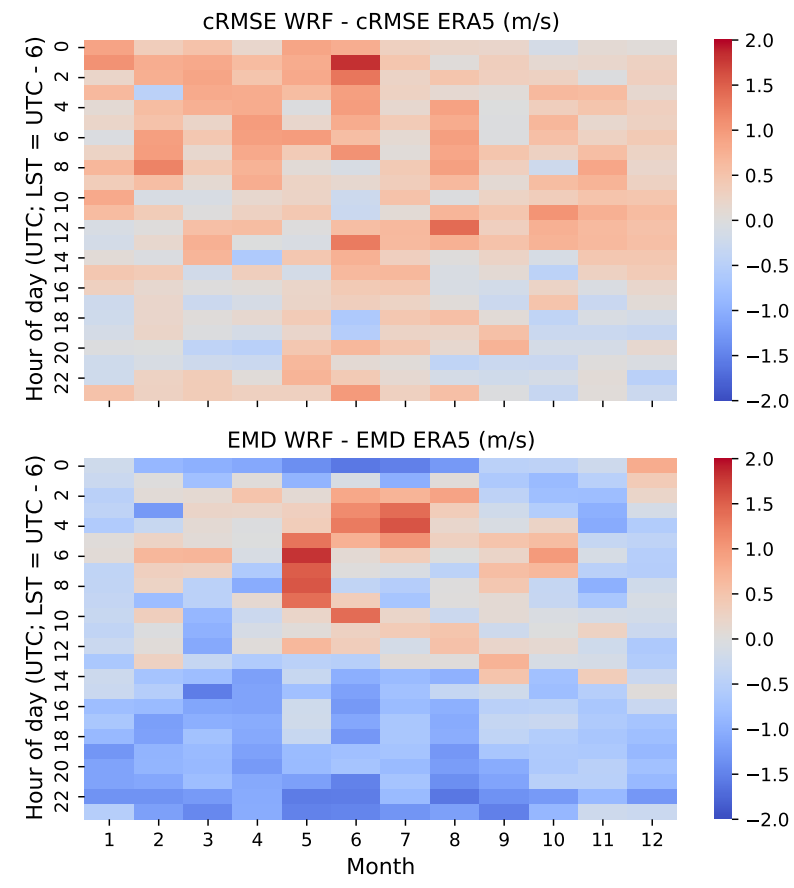
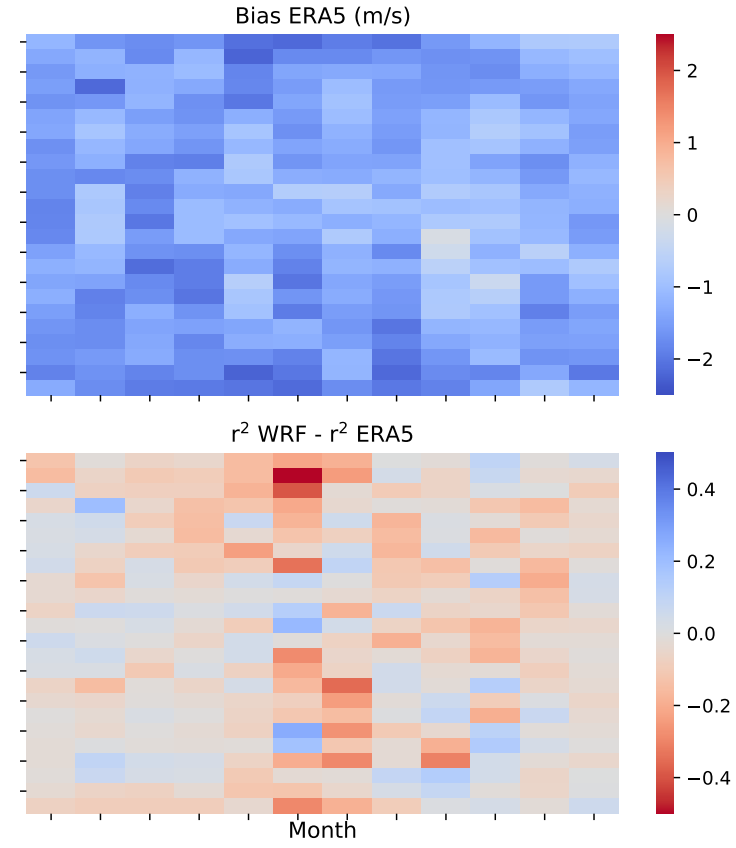

Figure 8. $24 \times 12$ heat maps at the SGP C1 site showing the diurnal and seasonal variability in the four performance metrics for the $91-\mathrm{m}$ wind speed.

analysis of bias confirms what was seen in Figure 7-that ERA-5 displays a negative bias for all months and hours, whereas WTK-LED shows mostly a positive bias during the night and a negative bias during the daytime, thus confirming that WTKLED overestimates the diurnal cycle throughout the year. While the daytime bias performance of WTK-LED does not change significantly throughout the year, we find a larger positive bias in summer nights, whereas in winter the bias is smaller. When looking at the differences in the cRMSE between WTK-LED and ERA-5, we find more instances where WTK-LED shows higher cRMSE values than ERA-5 during the nighttime than the daytime. As already noted for bias, we find a worse WTKLED performance during nighttime in summer months also in terms of cRMSE, correlation, and EMD. In general, WTK-LED 

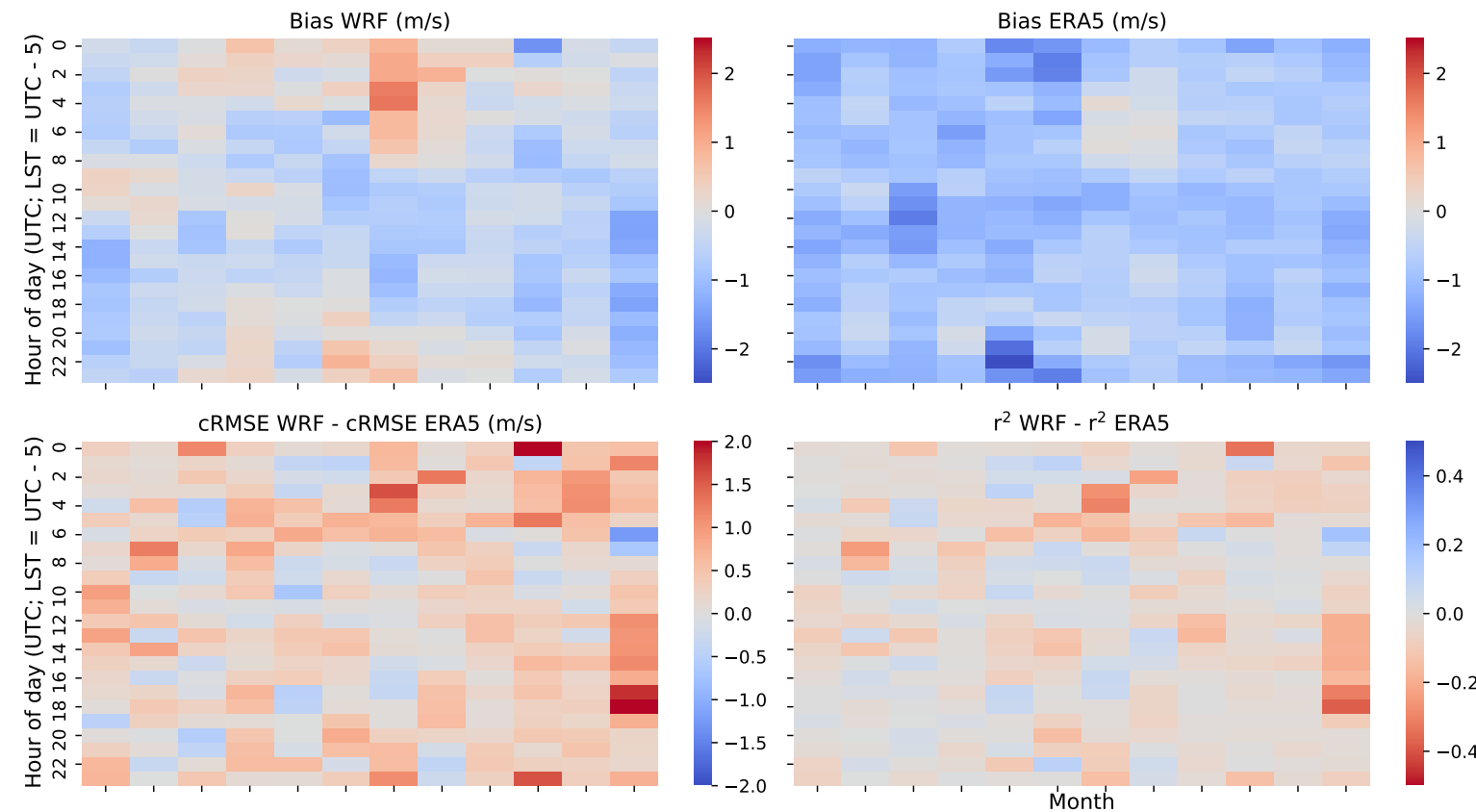

$r^{2}$ WRF - $r^{2}$ ERA5
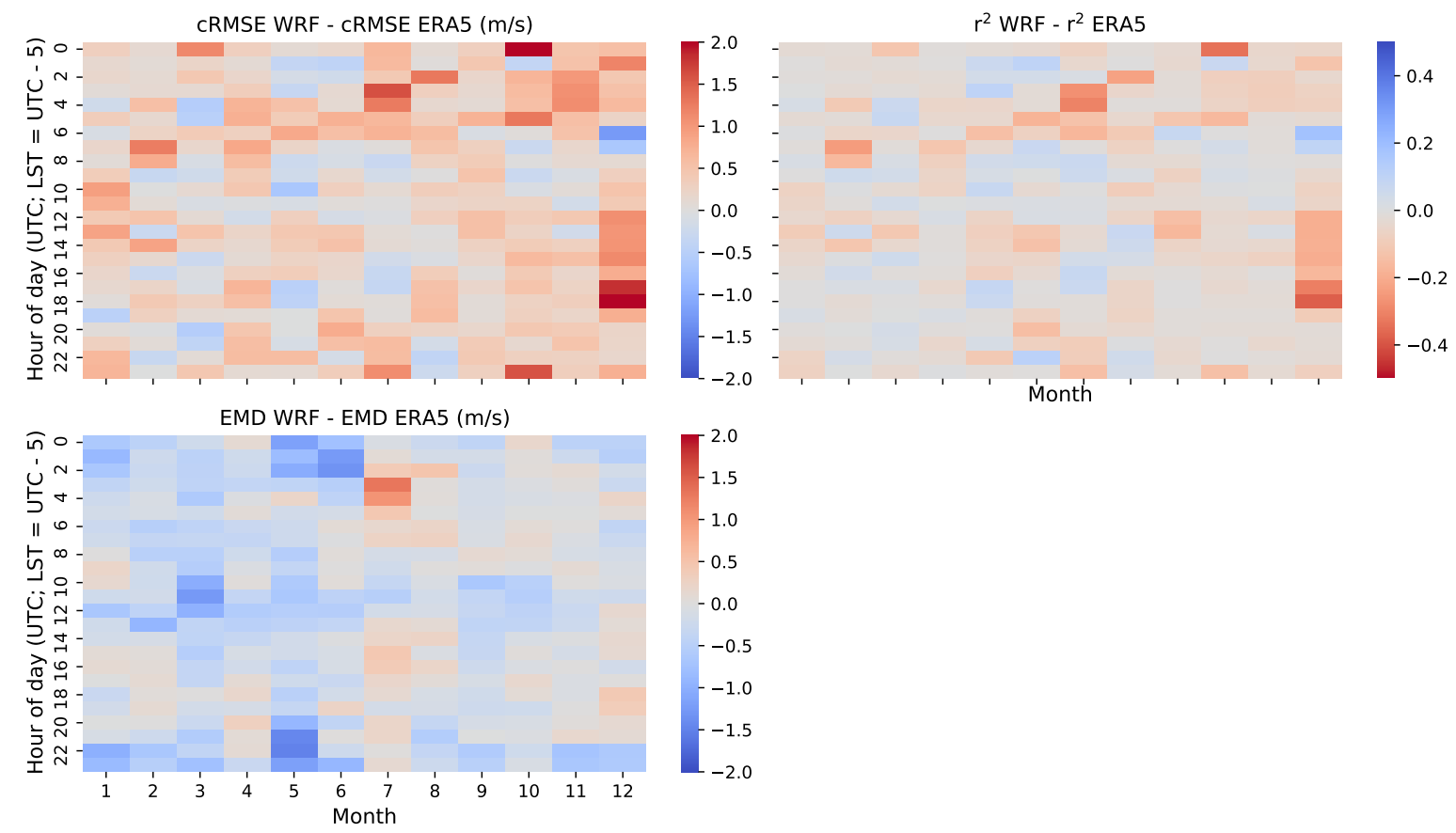

Figure 9. 24-x-12 heat maps at the location of the E05 lidar showing the diurnal and seasonal variability in the four performance metrics for the 98-m wind speed. Results from the E06 lidar are included in the Supplementary Materials.

shows significantly better performance than ERA-5 in terms of EMD during the daytime, whereas there are several instances during the nighttime, especially in the late spring and summer months, where ERA-5 outperforms WTK-LED.

At the offshore lidar location, ERA-5 shows a negative bias for all months and hours, similar to what was seen at SGP. WTK-LED displays more occurrences of positive biases in spring and summer months, especially at night, whereas a slightly negative bias is observed during the winter months at all hours. The overestimation of the observed diurnal cycle by WTK-LED is therefore more typical of summer months. However, little variability emerges when considering the relative performance of WTK-LED and ERA-5 in terms of the cRMSE, at both diurnal and annual scales. In fact, in the majority of cases, WTK-LED displays a higher cRMSE than ERA-5, but without any clear seasonal or diurnal pattern, thus making the interpretation of 

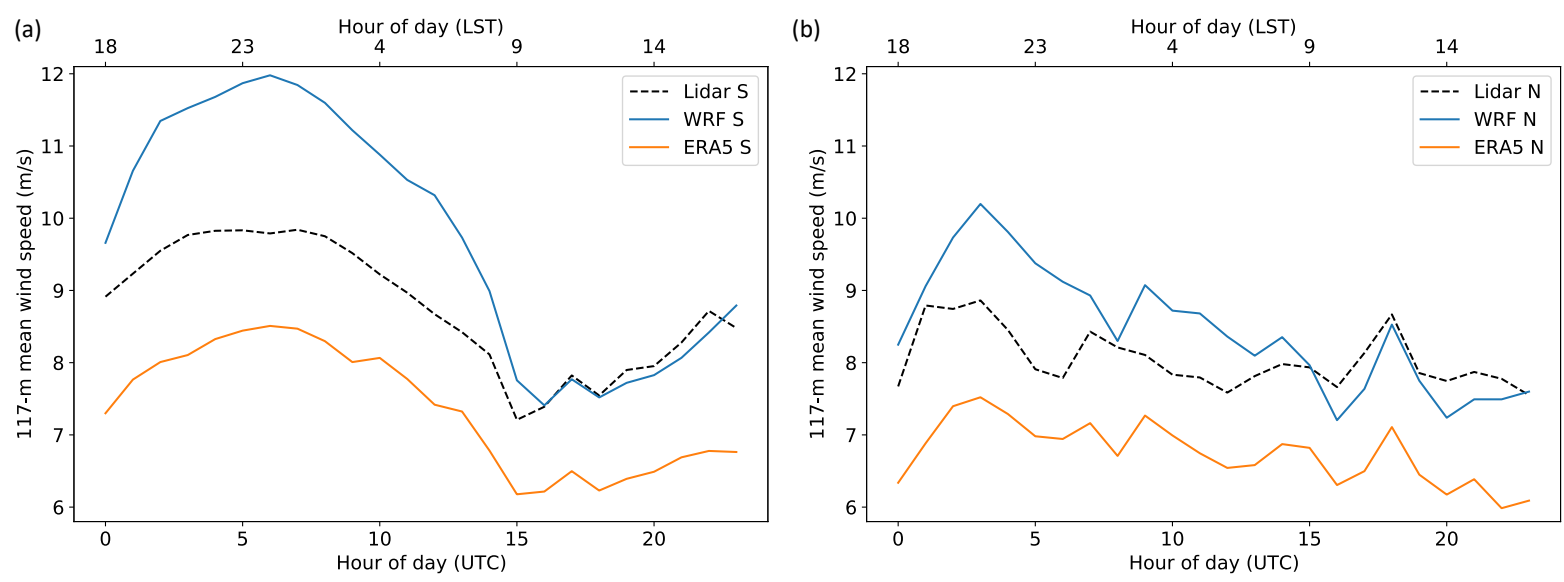

Figure 10. Average diurnal cycle of the $117-\mathrm{m}$ wind speed from lidar, WRF, and ERA-5 at the SGP C1 site for (a) southerly $\left(112^{\circ}-196^{\circ}\right)$ and (b) northerly $\left(315^{\circ}-45^{\circ}\right)$ wind flow.

the results murkier compared to the land-based case. Looking at the heat map for the EMD, a consistent seasonal or diurnal pattern is not clear, either. However, WTK-LED generally outperforms ERA-5 in terms of EMD, with its best performance in the spring.

Finally, we note how the land-based location, during 2018, is influenced by the presence of a large number of wind power plants in the vicinity (see map in Figure 1). As shown by Bodini et al. (in review), wakes from wind plants in the vicinity affect the lidar measurements at the $\mathrm{C} 1$ location, and wakes tend to be stronger in stable conditions. Because the WTK-LED predicts stronger winds at night than the lidar observes, some of the exaggerated diurnal cycle could be due to the fact that the WTK-LED does not incorporate effects from wind power plants. To further investigate this possibility, Figure 10 shows the hub-height wind speed average diurnal cycle at SGP for southerly flow (i.e., when the wind turbines are directly upwind of the lidar, panel (a)) and northerly flow (i.e., when the lidar measurements are unaffected by the wind power plants, panel (b)). We find that WTK-LED overestimates the hub-height wind speed especially for southerly flow, while only a slight overestimation is observed for the less frequent northerly flow. This result suggests how wind power plant wakes, which are not well represented by WTK-LED, might contribute to its strong overestimation of wind speed during stable conditions.

\section{Conclusions}

Accurate characterization of the wind resource aloft is a necessity for wind energy development. At land-based locations, direct observations of the wind resource at hub height are often challenging to collect due to a variety of reasons, including cost, complex topography, road access, and availability of electrical power. Offshore, collecting direct measurements of wind speeds aloft is even more challenging. Thus, NWP models and reanalysis products are often used to characterize the wind resource in the locations of interest for wind energy development. 
Using one year of lidar data at both land-based and offshore test sites, we evaluated the WRF model as run in the WTK-LED setup and the ERA-5 reanalysis product in their wind resource assessment skills. To evaluate each data product, we calculated four model performance metrics—bias, cRMSE, $r^{2}$, and EMD. WTK-LED shows a smaller bias than ERA-5 at both the considered locations for all of the stability conditions. However, ERA-5 outperforms WTK-LED in terms of cRMSE for all stability cases both at the land-based and offshore sites. A potential explanation for this underperformance of WTK-LED in terms of cRMSE is WTK-LED's exaggeration of the average diurnal cycle at both sites. In fact, when considering the diurnal variability of the WTK-LED bias, we find that WTK-LED generally shows a positive bias at night and more instances of negative biases during the daytime. ERA-5 is capable of well capturing the amplitude of the daily cycle in hub-height wind speed at the considered locations, albeit with a relatively constant negative bias throughout the diurnal cycle. Both WTK-LED and ERA-5 showed high correlation offshore, while at the land-based site the correlation was slightly reduced, likely because of the increased complexity in modeling the wind flow in conjunction with topographic effects. Analysis at both locations showed ERA-5 having a slightly stronger correlation than WTK-LED. Based on the analysis of the EMD, the wind speed distributions predicted by WTK-LED better match the observed distributions compared to the ERA-5 data in all stability conditions.

Our results show how there is not a clear and universal winner between WRF (in the WTK-LED setup) and ERA-5 when assessing their skills for wind resource assessment at these two locations, offshore and flat terrain on land. However, when weighting the relative performance of the two data sources, it is worth noting how bias correction techniques have been successfully applied in the wind energy sector (Stoffelen, 1998; Costoya et al., 2020), so that we can expect worse ERA-5 performance in terms of bias would be easier to accommodate when compared to the WTK-LED underperformance in terms of random error (cRMSE) and correlation. On the other hand, it is worth emphasizing that WTK-LED offers data at a finer spatial and temporal resolution, which represents an essential advantage over reanalysis products for specific wind energy related applications, such as grid integration analyses (Archer et al., 2017) and in locations with complex terrain. Clearly, it is important to stress that the results we found are specific to the sites considered in the analysis, which are both characterized by simple topography. Future work can replicate our proposed validation in more complex terrain, where the coarser resolution of the reanalysis products is likely to have a severe negative impact on their skills in accurately representing the wind flow at hub height. Such analyses could provide additional understanding about why the WTK-LED WRF setup struggled, in our analysis, in well representing the wind speed diurnal cycle aloft. Finally, follow-on work will explore whether representing wind power plants in WRF improves the WRF performance in the vicinity of active wind power plants (e.g., by using the WRF Wind Farm Parameterization (Fitch et al., 2012; Tomaszewski and Lundquist, 2020)) .

Data availability. Observations at the SGP site are publicly available at https://www.arm.gov/capabilities/instruments/dl. The NYSERDA lidar observations are publicly available at https://oswbuoysny.resourcepanorama.dnvgl.com. ERA-5 data are publicly available from the ECMWF's MARS archive. The open-source WRF model was used for the numerical weather prediction simulations. 
https://doi.org/10.5194/wes-2021-97

Preprint. Discussion started: 13 September 2021

(C) Author(s) 2021. CC BY 4.0 License.

(c) (i)

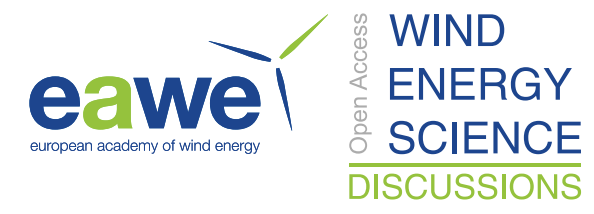

300 Author contributions. NB, MO, PM, and JKL envisioned the analysis. MO ran the offshore WRF simulations. CD, AP, and EY ran the land-based WRF simulations. VP analyzed the data, in close consultation with NB, and with general guidance from MO, PM, and JKL. VP and NB wrote the manuscript. All authors provided feedback on the paper draft.

Competing interests. The authors declare that they have no conflicts of interest.

Acknowledgements. This work was supported in part by the U.S. Department of Energy, Office of Science, Office of Workforce Development for Teachers and Scientists under the Science Undergraduate Laboratory Internship program. This research was performed using computational resources sponsored by the U.S. Department of Energy's Office of Energy Efficiency and Renewable Energy and located at the National Renewable Energy Laboratory. 
https://doi.org/10.5194/wes-2021-97

Preprint. Discussion started: 13 September 2021

(C) Author(s) 2021. CC BY 4.0 License.

\section{References}

Al-Yahyai, S., Charabi, Y., and Gastli, A.: Review of the use of numerical weather prediction (NWP) models for wind energy assessment,

Renewable and Sustainable Energy Reviews, 14, 3192-3198, https://doi.org/https://doi.org/10.1016/j.rser.2010.07.001, 2010.

Archer, C., Simão, H., Kempton, W., Powell, W. B., and Dvorak, M.: The challenge of integrating offshore wind power in the US electric grid. Part I: Wind forecast error, Renewable energy, 103, 346-360, https://doi.org/https://doi.org/10.1016/j.renene.2016.11.047, 2017.

Babić, K., Bencetić Klaić, Z., and Večenaj, Ž.: Determining a turbulence averaging time scale by Fourier analysis for the nocturnal boundary layer, Geofizika, 29, 35-51, 2012.

Bloomfield, H., Shaffrey, L., Hodges, K., and Vidale, P.: A critical assessment of the long-term changes in the wintertime surface Arctic Oscillation and Northern Hemisphere storminess in the ERA20C reanalysis, Environmental Research Letters, 13, 094004, https://doi.org/10.1088/1748-9326/aad5c5, 2018.

Bodini, N. and Optis, M.: The importance of round-robin validation when assessing machine-learning-based vertical extrapolation of wind speeds, Wind Energy Science, 5, 489-501, https://doi.org/https://doi.org/10.5194/wes-5-489-2020, 2020.

Bodini, N., Lundquist, J. K., and Kirincich, A.: US East Coast lidar measurements show offshore wind turbines will encounter very low atmospheric turbulence, Geophysical Research Letters, 46, 5582-5591, https://doi.org/https://doi.org/10.1029/2019GL082636, 2019.

Bodini, N., Lundquist, J. K., and Kirincich, A.: Offshore wind turbines will encounter very low atmospheric turbulence, in: Journal of Physics: Conference Series, vol. 1452, p. 012023, IOP Publishing, https://doi.org/10.1088/1742-6596/1452/1/012023, 2020.

Bodini, N., Lundquist, J. K., and Moriarty, P.: Wind plants can impact long-term local atmospheric conditions, Scientific Reports, in review.

Brower, M.: Wind resource assessment: a practical guide to developing a wind project, John Wiley \& Sons, 2012.

Browning, K. and Wexler, R.: The determination of kinematic properties of a wind field using Doppler radar, Journal of Applied Meteorology, 7, 105-113, https://doi.org/https://doi.org/10.1175/1520-0450(1968)007<0105:TDOKPO>2.0.CO;2, 1968.

Bureau of Ocean Energy Management: Outer Continental Shelf Renewable Energy Leases Map Book, Tech. rep., Bureau of Ocean Energy Management, https://www.boem.gov/sites/default/files/renewable-energy-program/Mapping-and-Data/Renewable_Energy_Leases_ Map_Book_March_2019.pdf, 2018.

Carbon Trust Offshore Wind Accelerator: Carbon Trust Offshore Wind Accelerator Roadmap for the Commercial Acceptance of Floating LiDAR Technology, Tech. rep., Carbon Trust, https://prod-drupal-files.storage.googleapis.com/documents/resource/public/Roadmap\% 20for\%20Commercial\%20Acceptance\%20of\%20Floating\%20LiDAR\%20REPORT.pdf, 2018.

Compo, G. P., Whitaker, J. S., Sardeshmukh, P. D., Matsui, N., Allan, R. J., Yin, X., Gleason, B. E., Vose, R. S., Rutledge, G., Bessemoulin, P., et al.: The twentieth century reanalysis project, Quarterly Journal of the Royal Meteorological Society, 137, 1-28, https://doi.org/https://doi.org/10.1002/qj.776, 2011.

Costoya, X., Rocha, A., and Carvalho, D.: Using bias-correction to improve future projections of offshore wind energy resource: A case study on the Iberian Peninsula, Applied Energy, 262, 114 562, https://doi.org/https://doi.org/10.1016/j.apenergy.2020.114562, 2020.

De Franceschi, M. and Zardi, D.: Evaluation of cut-off frequency and correction of filter-induced phase lag and attenuation in eddy covariance analysis of turbulence data, Boundary-Layer Meteorology, 108, 289-303, https://doi.org/https://doi.org/10.1023/A:1024157310388, 2003. Dee, D. P., Uppala, S. M., Simmons, A., Berrisford, P., Poli, P., Kobayashi, S., Andrae, U., Balmaseda, M., Balsamo, G., Bauer, d. P., et al.: The ERA-Interim reanalysis: Configuration and performance of the data assimilation system, Quarterly Journal of the royal meteorological society, 137, 553-597, https://doi.org/https://doi.org/10.1002/qj.828, 2011. 
https://doi.org/10.5194/wes-2021-97

Preprint. Discussion started: 13 September 2021

(C) Author(s) 2021. CC BY 4.0 License.

Dörenkämper, M., Olsen, B. T., Witha, B., Hahmann, A. N., Davis, N. N., Barcons, J., Ezber, Y., García-Bustamante, E., González-Rouco,

J. F., Navarro, J., Sastre-Marugán, M., SÄle, T., Trei, W., Žagar, M., Badger, J., Gottschall, J., Sanz Rodrigo, J., and Mann, J.: The Making of the New European Wind Atlas - Part 2: Production and Evaluation, Geoscientific Model Development Discussions, 2020, 1-37, https://doi.org/10.5194/gmd-2020-23, https://www.geosci-model-dev-discuss.net/gmd-2020-23/, 2020.

Draxl, C., Clifton, A., Hodge, B.-M., and McCaa, J.: The Wind Integration National Dataset (WIND) Toolkit, Applied Energy, 151, 355 366, https://doi.org/10.1016/j.apenergy.2015.03.121, http://www.sciencedirect.com/science/article/pii/S0306261915004237, 2015.

Fitch, A. C., Olson, J. B., Lundquist, J. K., Dudhia, J., Gupta, A. K., Michalakes, J., and Barstad, I.: Local and mesoscale impacts of wind farms as parameterized in a mesoscale NWP model, Monthly Weather Review, 140, 3017-3038, https://doi.org/10.1175/MWR-D-11$00352.1,2012$.

Frehlich, R., Meillier, Y., Jensen, M. L., Balsley, B., and Sharman, R.: Measurements of boundary layer profiles in an urban environment, Journal of applied meteorology and climatology, 45, 821-837, https://doi.org/https://doi.org/10.1175/JAM2368.1, 2006.

Gelaro, R., McCarty, W., Suárez, M. J., Todling, R., Molod, A., Takacs, L., Randles, C. A., Darmenov, A., Bosilovich, M. G., Reichle, R., et al.: The Modern-Era Retrospective Analysis for Research and Applications, version 2 (MERRA-2), Journal of Climate, 30, 5419-5454, https://doi.org/https://doi.org/10.1175/JCLI-D-16-0758.1, 2017.

Greene, S., McNabb, K., Zwilling, R., Morrissey, M., and Stadler, S.: Analysis of vertical wind shear in the Southern Great Plains and potential impacts on estimation of wind energy production, International journal of global energy issues, 32, 191-211, https://doi.org/10.1504/IJGEI.2009.030651, 2009.

Hahmann, A. N., Sile, T., Witha, B., Davis, N. N., Dörenkämper, M., Ezber, Y., García-Bustamante, E., González Rouco, J. F., Navarro, J., Olsen, B. T., and Söderberg, S.: The Making of the New European Wind Atlas, Part 1: Model Sensitivity, Geoscientific Model Development Discussions, 2020, 1-33, https://doi.org/10.5194/gmd-2019-349, https://www.geosci-model-dev-discuss.net/gmd-2019-349/, 2020.

Hersbach, H., Bell, B., Berrisford, P., Hirahara, S., Horányi, A., Muñoz-Sabater, J., Nicolas, J., Peubey, C., Radu, R., Schepers, D., et al.: The ERA5 global reanalysis, Quarterly Journal of the Royal Meteorological Society, 146, 1999-2049, https://doi.org/https://doi.org/10.1002/qj.3803, 2020.

King, J., Clifton, A., and Hodge, B.-M.: Validation of power output for the WIND Toolkit, Tech. rep., National Renewable Energy Lab.(NREL), Golden, CO (United States), https://doi.org/https://doi.org/10.2172/1159354, 2014.

Kubik, M., Brayshaw, D. J., Coker, P. J., and Barlow, J. F.: Exploring the role of reanalysis data in simulating regional wind generation variability over Northern Ireland, Renewable energy, 57, 558-561, https://doi.org/https://doi.org/10.1016/j.renene.2013.02.012, 2013.

Lieberman-Cribbin, W., Draxl, C., and Clifton, A.: Guide to using the WIND toolkit validation code, Tech. rep., National Renewable Energy Lab.(NREL), Golden, CO (United States), https://doi.org/https://doi.org/10.2172/1166659, 2014.

Livingston, H. G. and Lundquist, J. K.: How many offshore wind turbines does New England need?, Meteorological Applications, 27, e1969, https://doi.org/https://doi.org/10.1002/met.1969, 2020.

Molina, M., Gutiérrez, C., and Sánchez, E.: Comparison of ERA5 surface wind speed climatologies over Europe with observations from the HadISD dataset, International Journal of Climatology, https://doi.org/https://doi.org/10.1002/joc.7103.

Musial, W., Heimiller, D., Beiter, P., Scott, G., and Draxl, C.: Offshore wind energy resource assessment for the United States, Tech. rep., National Renewable Energy Laboratory (NREL), Golden, CO (United States), https://doi.org/https://doi.org/10.2172/1324533, https:// www.nrel.gov/docs/fy16osti/66599.pdf, 2016.

Newsom, R.: Doppler lidar (DL) handbook, Tech. rep., DOE Office of Science Atmospheric Radiation Measurement (ARM) Program, 2012. 
https://doi.org/10.5194/wes-2021-97

Preprint. Discussion started: 13 September 2021

(C) Author(s) 2021. CC BY 4.0 License.

OceanTech Services/DNV GL: NYSERDA Floating Lidar Buoy Data, https://oswbuoysny.resourcepanorama.dnvgl.com.

of Ocean Energy Management, B.: Outer Continental Shelf Renewable Energy Leases Map Book, Tech. rep., https://www.boem.gov/sites/ default/files/documents/oil-gas-energy/Renewable_Energy_Leases_Map_Book_March_2021_v2.pdf, 2021.

Optis, M., Bodini, N., Debnath, M., and Doubrawa, P.: Best Practices for the Validation of U.S. Offshore Wind Resource Models, Tech. rep., National Renewable Energy Laboratory (NREL), Golden, CO (United States), https://doi.org/https://doi.org/10.2172/1755697, https: //www.nrel.gov/docs/fy21osti/78375.pdf, 2020a.

Optis, M., Rybchuk, O., Bodini, N., Rossol, M., and Musial, W.: 2020 Offshore Wind Resource Assessment for the California Pacific Outer Continental Shelf, Tech. rep., National Renewable Energy Lab.(NREL), Golden, CO (United States), https://doi.org/https://doi.org/10.2172/1677466, 2020b.

Ramon, J., Lledo, L., Torralba, V., Soret, A., and Doblas-Reyes, F. J.: What global reanalysis best represents near-surface winds?, Quarterly Journal of the Royal Meteorological Society, 145, 3236-3251, https://doi.org/https://doi.org/10.1002/qj.3616, 2019.

Rose, S. and Apt, J.: What can reanalysis data tell us about wind power?, Renewable Energy, 83, 963-969, https://doi.org/https://doi.org/10.1016/j.renene.2015.05.027, 2015.

Rybchuk, A., Optis, M., Lundquist, J. K., Rossol, M., and Musial, W.: A Twenty-Year Analysis of Winds in California for Offshore Wind Energy Production Using WRF v4. 1.2, Geoscientific Model Development Discussions, pp. 1-41, https://doi.org/https://doi.org/10.5194/gmd-2021-50, 2021.

Schwartz, M., George, R., and Elliott, D.: The use of reanalysis data for wind resource assessment at the National Renewable Energy Laboratory, Tech. rep., National Renewable Energy Lab., Golden, CO (US), https://www.osti.gov/biblio/10425, 1999.

Sheridan, L. M., Krishnamurthy, R., Gorton, A. M., Shaw, W. J., and Newsom, R. K.: Validation of Reanalysis-Based Offshore Wind Resource Characterization Using Lidar Buoy Observations, Marine Technology Society Journal, 54, 44-61, https://doi.org/https://doi.org/10.4031/MTSJ.54.6.13, 2020.

Skamarock, W. C., Klemp, J. B., Dudhia, J., Gill, D. O., Liu, Z., Berner, J., Wang, W., Powers, J. G., Duda, M. G., Barker, D. M., et al.: A description of the advanced research WRF model version 4, National Center for Atmospheric Research: Boulder, CO, USA, p. 145, https://doi.org/http://dx.doi.org/10.5065/D68S4MVH, 2019.

Smith, E. N., Gibbs, J. A., Fedorovich, E., and Klein, P. M.: WRF Model study of the Great Plains low-level jet: Effects of grid spacing and boundary layer parameterization, Journal of Applied Meteorology and Climatology, 57, 2375-2397, https://doi.org/https://doi.org/10.1175/JAMC-D-17-0361.1, 2018.

Smith, E. N., Gebauer, J. G., Klein, P. M., Fedorovich, E., and Gibbs, J. A.: The Great Plains low-level jet during PECAN: Observed and simulated characteristics, Monthly Weather Review, 147, 1845-1869, https://doi.org/https://doi.org/10.1175/MWR-D-18-0293.1, 2019.

Soares, P. M., Lima, D. C., and Nogueira, M.: Global offshore wind energy resources using the new ERA-5 reanalysis, Environmental Research Letters, 15, 1040a2, https://doi.org/https://doi.org/10.1088/1748-9326/abb10d, 2020.

Song, J., Liao, K., Coulter, R. L., and Lesht, B. M.: Climatology of the low-level jet at the southern Great Plains atmospheric boundary layer experiments site, Journal of Applied Meteorology, 44, 1593-1606, https://doi.org/https://doi.org/10.1175/JAM2294.1, 2005.

415 Stoffelen, A.: Toward the true near-surface wind speed: Error modeling and calibration using triple collocation, Journal of geophysical research: oceans, 103, 7755-7766, https://doi.org/https://doi.org/10.1029/97JC03180, 1998.

Taylor, K. E.: Summarizing multiple aspects of model performance in a single diagram, Journal of Geophysical Research: Atmospheres, 106, 7183-7192, https://doi.org/https://doi.org/10.1029/2000JD900719, 2001. 
https://doi.org/10.5194/wes-2021-97

Preprint. Discussion started: 13 September 2021

(c) Author(s) 2021. CC BY 4.0 License.

(c) (i)

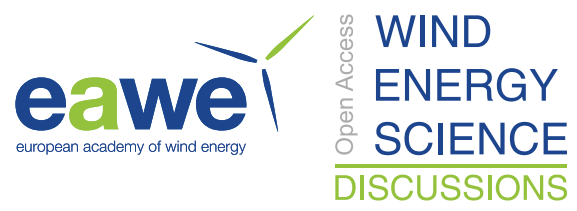

Tomaszewski, J. M. and Lundquist, J. K.: Simulated wind farm wake sensitivity to configuration choices in the Weather Research and

Forecasting model version 3.8. 1, Geoscientific Model Development, 13, 2645-2662, https://doi.org/https://doi.org/10.5194/gmd-13-2645$2020,2020$.

Zheng, C.-w., Xiao, Z.-n., Peng, Y.-h., Li, C.-y., and Du, Z.-b.: Rezoning global offshore wind energy resources, Renewable Energy, 129, 1-11, https://doi.org/https://doi.org/10.1016/j.renene.2018.05.090, 2018. 